This item was submitted to Loughborough's Research Repository by the author.

Items in Figshare are protected by copyright, with all rights reserved, unless otherwise indicated.

\title{
Cartoons beyond clipart: a computer tool for storyboarding and storywriting
}

PLEASE CITE THE PUBLISHED VERSION

PUBLISHER

(C) Elsevier

VERSION

AM (Accepted Manuscript)

LICENCE

CC BY-NC-ND 4.0

\section{REPOSITORY RECORD}

Madden, Mark, Paul Wai Hing Chung, and Christian W. Dawson. 2019. "Cartoons Beyond Clipart: A Computer Tool for Storyboarding and Storywriting”. figshare. https://hdl.handle.net/2134/5452. 
This item was submitted to Loughborough's Institutional Repository (https://dspace.lboro.ac.uk/) by the author and is made available under the following Creative Commons Licence conditions.

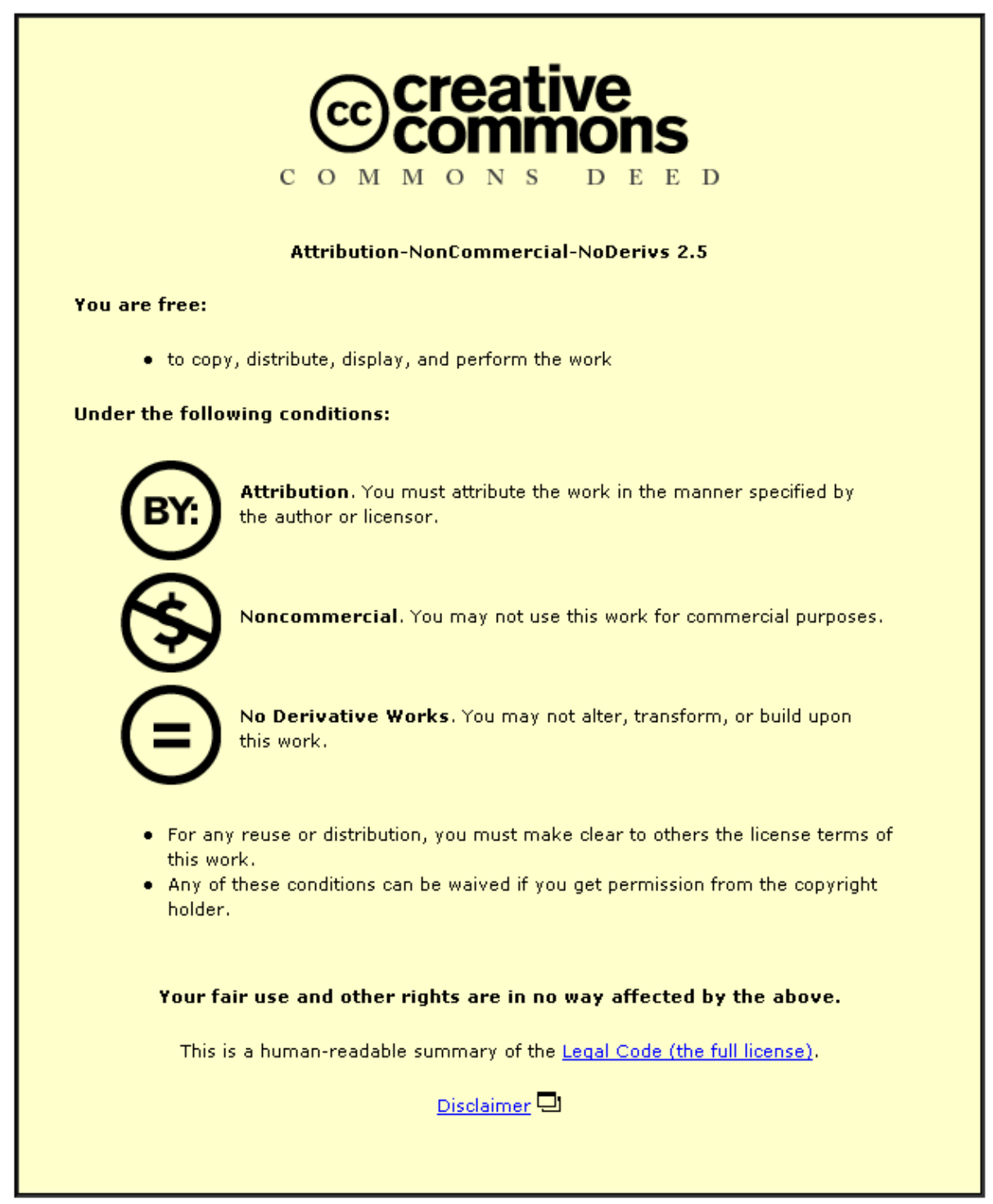

For the full text of this licence, please go to: http://creativecommons.org/licenses/by-nc-nd/2.5/ 


\title{
Cartoon beyond clipart: a computer tool for storyboarding and storywriting
}

\author{
M. Madden, P.W.H. Chung and C.W. Dawson \\ Department of Computer Science \\ Loughborough University \\ Loughborough LE11 3TU, UK
}

\begin{abstract}
This paper describes the motivation, proposal, and early prototype testing of a computer tool for story visualisation prior to storywriting. An analysis of current software for making various types of visual story is made; this identifies a gap between software which emphasises preset banks of artwork, and software which emphasises low-level construction and/or drawing. A proposal is made to fill this gap, and a prototype implementation of the proposal is described in the context of a school-based study with Year 5, covering ages 9-10 years. Results from this prototype study both validate the novel proposal made and demonstrate that children are capable of more complex graphical interaction than most current software permits.
\end{abstract}

\section{Introduction}

An emerging theme from recent UK English and literacy education emphasises the links between visual, specifically moving image, stories and written ones. The Government's 2005 report on the national curriculum explicitly calls for "moving image texts" to be more fully used throughout English teaching (Ofsted, 2005), and there is suggestive evidence that the use of such texts can benefit English and literacy across a wide age range (Burn and Leach, 2004; Parker, 2002; Oldham, 1999; Marsh and Thompson, 2001); this may have links to theories of writing (Madden et al, 2004). Further afield from the UK too, there is interest in the role which moving image texts may play in students' communicative and narrative abilities; Erstad's report (2002) gives a Norwegian perspective, Fee and Fee (2003), Donovan (2003), Bailey et al (2006), and MacGregor (2002) describe related topics studied in the USA, and Burn and Leach (2004) describe how the English curricula of Canada, Australia and New Zealand also consider the medium.

In addition to simply 'reading' moving image texts, educators attach considerable importance to making them (bfi Primary Education Working Group, 2003; Reid et al, 2002; Parker, 1999; Sefton-Green and Parker, 2000), and it is here that software, digital media and their associated plasticity can be particularly helpful (Burn and Parker, 2001). This paper will contend, however, that current software for making such texts leaves room for extension, and goes on to propose and test one possible approach. In doing so it intends neither to advertise a polished product nor to showcase effective pedagogy, but rather to contextualise and motivate the development of a new software tool and present formative experimental data on that tool's use in something approaching a real classroom context. This is done so as to determine whether the concept which the tool embodies is worth progressing.

The remainder of the paper is structured as follows. The next section surveys and assesses software which may be used for some kind of moving image production. The 
following section builds on that assessment to propose one way of going beyond the affordances currently offered. Prototype software based on that proposal was subsequently developed, and the next section discusses a field study which used this software in the context of a visualisation and writing exercise. Conclusions and next steps are summarised in the final section.

\section{Current Software}

\subsection{Scope of Review and Criteria for Analysis}

In order to establish what scope exists for new software to support students in moving image production, a review of the current context is needed; the software selected for review extends beyond obvious moving image tools such as digital video or animation programs to include presentation, storyboarding and other tools. This is so because the essential elements of the mode of the moving image, termed the kineikonic mode by Burn and Parker (2003a,b,2001), may be present in things which are not themselves moving images. These elements are twofold. First is 'filming', for example framing an image, choosing what to include, what to exclude, and arranging the elements within the image relative to each other. The second is 'editing', which includes the sequencing of and transitions between images, scenes, and so on. According to Burn and Leach, the kineikonic mode "operates as a combinatorial mode which assembles and integrates other modes (speech, image, gesture, music) through its own 'grammar' of filming and editing".

Consequently, a kineikonic story may be expressed as a film but also as a comic strip, using spatial sequencing to replace temporal sequencing; as McCloud (1993) points out, "space does for comics what time does for film"; this is precisely what pre-production storyboards, for example, rely on. Hence, any tool which allows users to make pictures and place them in sequence shall be analysed for the affordances it offers in telling stories through the kineikonic mode. This criterion admits a great many specific titles and so the intention below is to cover a representative range, but not provide an exhaustive list. The looser but simpler term "visual story" shall be adopted from hereon; although terms are not synonymous, every kineikonic story must by definition have used 'filming' in some sense and so must be visual.

Each software title will be examined for the opportunities it provides in two particular areas of interest which are argued to form two important elements of the kineikonic mode.

- Characterisation: how much flexibility of expression is provided? The depiction of characters is obviously central to most, although not necessarily all, visual stories. When examining software story-making opportunities, then, it is useful to ask to what extent characters can show different emotions and actions, and whether characters can be changed, customised or created from scratch.

- The camera's role: can different shot distances and types be used? The intended meaning of a given picture influences how it is shown, a point emphasised in educational resources (see, for example, Barrance, 2004). Therefore, the degree to which a given title allows users to change how a picture is viewed is an important factor in its support of moving image narrative. This is not a question of whether an explicit vocabulary of the camera, shot distance, angle or type is used, but whether the software provides mechanisms to deploy different shots. For example, the ability to zoom allows the deployment of different shot distances, even if they are not named as such. 
Choosing only these criteria is not intended to imply that they are the only criteria which 'matter' in software. Instead the assertion is made that these areas are of particular interest when considering software for visual story production and when considering what scope exists for further development in such software. It might be thought that the features described are too sophisticated for students to grasp; however a look at the titles themselves shows that this is not the case. Even software aimed at a comparatively young audience such as Kahootz or Virtual Puppeteers (see below) incorporates aspects such as 3D camera navigation and sophisticated character design, suggesting that an analysis of such facilities is appropriate.

Much of the software reviewed is designed directly for children. That which is not, for example Flash or Machinima, is included because, despite being a potentially complex or professional-level tool, evidence has been found of its use by children in educational contexts. This is noted in the appropriate sections. The amount of training which may be required for students to thoroughly learn any tool is intentionally not considered, because the review intends to compare features and characteristics of software, not suitability for a particular classroom - all that is required for a title to be considered in the review is that it has been used in some educational setting for visual story production.

A final point to note is that computer games are excluded from the review; to see why, consider the two ways to use computer games in teaching and learning: playing a game in an educational context, and authoring a game. Playing a game generally offers a user little opportunity to express a narrative visually using filming and editing; the focus is more on interacting with the story, the game world or a combination of the two. The deliverable product of game playing is the transient experience itself; by contrast, the benefits others cite for linking moving image production activities with conventional literacy rest on the idea of making visual stories as products in themselves - it is interesting to note that, in the case studies found in the Becta report on computer games in education (Becta, 2002), none of the intended learning outcomes from using the games explicitly mention storytelling or narrative. Considering game authoring, computer games certainly do employ the kineikonic mode (Burn and Parker, 2003a), so authoring a computer game does entail the production of a visual story. However, designing a game to be played is quite distinct from designing a visual story to be viewed; game-making is distinguished by the need to consider interaction controls, scripting and programming in addition to mediating a visual story. Making games has educational value, but game authoring should be recognised as being a distinct activity from authoring a non-interactive visual story. The literacy benefits cited earlier all originate from reading and authoring non-interactive narrative, and this is considered good reason to exclude game authoring. Thus computer games in education encompass a quite distinct set of activities from producing non-interactive visual stories, neither nullifying nor subsuming the latter; instead they form separate topics which deserve to be considered separately.

The software review is split into two sections. The first considers what shall be termed 'content-centred' software, whose rough defining feature shall be taken to be a primary reliance on pre-supplied characters and artwork. This does not preclude tools which also allow some user-defined input, so long as such user input can only supplement the provided content rather than replace it outright. The contrasting approach is termed 'buildcentred', in which a program provides sufficient tools for user-created content to take an equal or dominant role compared to pre-supplied content. The boundary here is blurred, but it is suggested that there is a marked and generally quite obvious difference in intention between the two categories. The review aims to illustrate that distinction. Tables 1 and 2 summarise each tool in light of the three review aspects. 


\subsection{Available Content-Centred Software}

- Kar2ouche (Immersive Education): described as a storyboarding and animation program. Learners assemble pictures using a background image and character and object clipart. Pictures are placed in a sequence which can be used to effect presentations and stopmotion animations. Custom backgrounds can be imported, allowing users to create their own locations for scenes. One use of Kar2ouche is described by Birmingham and Davies (2001).

- MediaStage (Immersive Education): designed to allow the creation and filming of 3D sets, populated by 3D actors chosen from a gallery. Characters can be made to talk using a text-to-speech feature, and have a range of presetactions and animations.

- Machinima: an umbrella term for adapting computer game resources, be they characters, objects or environments, for film-making. The exact way this is accomplished varies with the game; some allow characters to be scripted and filmed in custom levels, others require that a normal multiplayer game be set up, with one player being the camera and others acting out lines. Biever (2003) provides a further introduction, and events such as the SummerTech Machinima Children's Film Festival (see www.summertech.net), aimed to allow children from age 10 and above to create their own machinima, provide evidence that this method of visual story production is accessible to children.

\section{- Kahootz (Australian Children's Television Foundation): emerged}

from work described by Bennett et al (2000). It allows users to construct 3D worlds and animations by selecting prebuilt environments and choosing characters and objects from a gallery. Users can also draw 2D elements and textures with the 'notepad' facility, and are encouraged in sharing their work online via the linked online community.

- Picture Writer (JVSoft): intended to allow users to make themed pictures and story books by using clipart and backgrounds centred on a given story or topic. Text can be read back to users with text-to-speech.

- $i$-Theatre Lab (Mantra Lingua): works from the premise of building a virtual cutout theatre production. Simple sets can be designed, characters placed and animations made. Also supplied with the software are printouts of set and character art which can be used to make a physical analogue of the virtual theatre.

- MoPix (Film Education): designed to help students explore concepts of editing and sequence. It provides a selection of short video clips, all centred on a particular theme, for example a phone call, and allows users to sequence these clips together to tell the story of the events in different ways.

\subsection{Available Build-Centred Software}

- Virtual Puppeteers (Squidsoup): allows users to create their own characters with 3D virtual plasticine, and to build their own sets for these puppets to act in. Models can be painted and their motion around the setanimated.

- Presentation and Other Authoring Software: category groups authoring tools for slide shows or other sequential visual content, for example multimedia story books. Exemplars are Textease Presenter CT (Softease), Textease CT (Softease), BlackCat SlideShow (BlackCat), 2Create A Story (2Simple), HyperStudio (Sunburst Technology), EasyBook Deluxe (Sunburst Technology), KidPix Deluxe 4 (Broderbund), The Complete Animator (lota Software), and ImageBlender (Tech-4-Learning). All are really aimed at making quite general products based around pictures and text, and this results in the absence of an idea 
of a camera through which the work is framed. Characterisation may only be expressed by drawing from scratch or using unmodifiable clipart.

- Video Compositing and Animators: category groups software for editing and sequencing digital video clips. Exemplars are Textease Movies CT (Softease), iMovie (Apple), Windows Movie Maker (Microsoft), 2Animate (2Simple), I Can Animate (Kudlian Soft), Digital Movie Creator 2 (Digital Blue), VideoBlender2 (Tech4Learning), VideoStudio 9 (Ulead) and Media 100 (Media 100); some are aimed specifically at filming stop-motion animation, and others more generally at video editing. All titles here are designed not to help with the creation of visuals, but rather their sequencing, so it is not possible to construct different camera shots within the programs themselves. However, ${ }_{228}$ the device used to capture the video in the first place certainly could allow a great many kinds of camera shot. Similarly to MoPix, these titles do not aim to supply characters as separate entities of any kind.

- Flash (Adobe): Flash has often been used by education professionals for creating educational content, but the notion of having students create Flash content is gaining ground. For example, the Flash Classroom (http://www.flashclassroom.com) shows evidence of 12 to 13 year-olds (Australian Year 7) successfully making pictures and animations.

- Clover: Developed and described by Bailey et al (2006), Clover has been designed to allow 10 to 14 year-olds to create their own animated stories, principally for relating realworld situations and experiences in stories referred to as "vignettes". It integrates tools for planning, scripting, character design, scene design and animation, notably offering substantial process support for these stages.

The main inferences are drawn from the information above. The first concerns the division between the content-centred and build-centred approaches to creating visuals. These may be characterised by the support for depiction they offer and the range of depiction they allow; a content-centred tool tends to rely on a preset, 'clipart-like', bank of resources, and providing this ready-made set of symbols for making meaning aids expression (SeftonGreen, 1999) and speeds production (Birmingham and Davies, 2001). This makes it possible to generate a limited class of pictures very easily, and might be described as offering low range and high support. A build-centred tool emphasises flexibility and power; it allows a user to depict whatever s/he wants, but not necessarily with ease. It can thus be said to offer high range and low support. Arguably, character visualisation is especially polarised in this respect, being either strongly content-centred by restricting the range, pose and facial expression of characters, or strongly build-centred in allowing great power of expression at the expense of supporting easy depiction. It is notable that no tool seems to offer both range and support.

\section{Proposing a New Tool for Visual Storytelling}

The observations above are now used to motivate and develop a proposal for a new visual storytelling tool. To support use of the kineikonic mode, it must at least allow pictures ${ }_{271}$ to be made and placed in sequence. Added to this are the following proposals.

\subsection{Bridging the Content/Build-Centred Gap}

The objective here is to offer a new compromise between the range of depiction which a tool makes possible and the support for depiction which it offers. It is suggested that these benefits may be combined by employing Burn and Parker's notion of the transformation of digital resources (2001); the starting point is their observation regarding the way students 
used a vector drawing program to create and modify characters by manipulating and transforming shapes, tugging at their geometric control points. Burn and Parker identify transformation as a concept enhanced by ICT, and specifically here the vector nature of the drawings. It is one channel through which digital media can offer a powerful provisionality and flexibility of inscription; provided the data is preserved in an appropriate format, a digital product such as a character, a scene or an animation can forever be reworked and retransformed, and new meanings brought from it, and this is one attribute which sets digital media apart from, for example, pencil and paper.

This kind of transformation provides a useful way to offer both range and support in depiction; initial 'starting point' characters can either be drawn much as in build-centred tools, or supplied in a clipart-like bank are they are in content-centred tools but transformed far beyond clipart norms, much more easily than is possible simply by redrawing from scratch. Such a feature is to be implemented using what will be termed a 2.5-dimensional 'enhanced-frontal-orientation' approach. This starts with a twodimensional vector drawing of a character, pictured from a straight-on perspective with arms out at the sides in what is sometimes described as a "canonical frontal orientation" (Golomb, 1999; Davis, 1985). The normally 2D control points of this vector drawing shall be stored in 3D space and mapped to a 3D skeleton, so that the character may be posed in whatever orientation the user desires. The skeleton is to be manipulated by dragging endpoints of limbs with the mouse, and using principles of inverse kinematics to obtain 3D parameters from this $2 \mathrm{D}$ input.

In addition to posing, transformation should be allowed by warping, that is, moving any of the control points of a given curve within a plane of a particularbone's coordinate frame, so that the entire appearance of a character, and crucially their expression, may change.

The proposed effect leads to something like a more flexible version of a paper cutout character; it remains essentially flat but can bend out of the plane and be viewed from any angle. It can act as a powerful enabler for inscription, as it allows one to make many meanings from a single character drawing; Fig. 1, produced with the aid of an early proof of concept implementation, illustrates this point. The enhanced-frontal-orientation approach aims to help users leverage the canonical depiction strategy to achieve a greater range of representation.

\subsection{Camera Considerations}

The scope of the software review above included any software which could be used to make pictures, irrespective of whether it was possible to alter the point of view of a notional camera in those pictures. However, if the proposed visual storyteller is really to support kineikonic storytelling, it becomes necessary to allow at least some latitude for varying camera angle and shot distance. An important design issue to address concerns the freedom of manipulation to be offered; shall users be able to fly the viewpoint to any location in a fully 3D scene, or will they be more constrained?

A fully 3D 'flyable' camera is likely only to be justified if the ability to move to any possible viewpoint offers real visual benefits. This in turn requires fully $3 D$ sets, which seems to significantly increase the complexity of the proposed tool. This, and the philosophy of taking and extending 2D representations presented above, suggest that an appropriate approach lies in the following alternative. Treat the camera as being fixed above a notional infinite 'page' which contains characters and artwork in three dimensions, but which hides use of the depth dimension from the user. Allow the camera to move 'horizontally' and 'vertically' around the page, and to zoom in and out, and all the ingredients necessary to 
choose the framing of a shot and to construct a variety of shot distances are provided. This is conceptually similar to the way in which hand-drawn animations are filmed; Fig. 2 gives some indication of the concept.

In addition to shot framing and distance, it is proposed to allow the camera to tilt up and down to some extent, in much the same way that a person looking at a poster can tilt their head up and down to look at different parts of it. This allows the construction of low- and high-angle shots, which are often used to signify power relationships between characters, and which thus may be worth allowing in a storytelling tool. In the interests of preserving a remnant of simplicity, no other camera manipulation will be allowed.

This approach allows scenes to be created by importing 2D artwork directly, without requiring that $3 \mathrm{D}$ models be constructed. In the spirit of extending purely two-dimensional resources, it is proposed that bitmap images be effectively texture-mapped to planes so that they, like characters, can be rotated out of the plane of the page.

\subsection{Implementation}

The concepts sketched out above were implemented in Java; a proof-of-concept enhanced-frontal-orientation character was first developed, and then this facility was generalised and integrated into a basic prototype of the whole proposal. Following an informal school-based test of the former proof-of-concept, it was judged that the prototype would best initially be trialled with children at the upper half of the 7-11 year range; although the informal test showed younger children were able to purposefully use all the features of the proof-of-concept character, older children used those same features more extensively.

Naturally, the prototype is precisely that, exhibiting a good share of limitations. Perhaps the greatest of these lies in the fact that it is not currently possible for learners to create their own posable characters; nothing in principle prevents this feature but insufficient time was available to make it happen. It therefore falls short of the aspiration to truly bridge the content/build-centered gap identified above and must be described as content-centered as it relies firmly on characters which have been provided for learners in advance.

Regarding other limitations, even considering just graphical capabilities, a great many enhancements and developments can be easily imagined. However, the prototype's main aim is to gather formative data on the proposal's feasibility rather than to hold up a fully polished product, so its relatively unrefined nature as compared to, for example, modern games, is considered acceptable. Additionally, the graphical sophistication of the latter is not reflected in the kind of art which children and adolescents generally make (compare the resources found in these games with the examples shown by Bailey et al, 2006, which students made themselves). Thus the more elaborate and detailed presupplied content becomes, the greater the danger that it will become more difficult to freely modify, transform and be included alongside user-generated content.

\section{Prototype Study}

This section describes a study designed to provide formative data as to the proposed software's feasibility for use by children and its possible educational role in conventional literacy. Of particular interest is the extent to which the character pose and warp functions and the camera control functions are used by participants during the task, though a number of other issues will also be examined. 
The study is deliberately small-scale and formative, aiming to use a reasonable authentic, naturalistic setting to test and refine the design assertions made above. No generalisation to a general population is intended.

\subsection{Software Design}

The software presents a sequence of 'stage view' screens like a series of pages as shown in Fig. 3. Each stage view shows its stage's shots as thumbnails placed on a free-form 'page'; no shot to-shot sequencing is enforced, so that a thumbnail may be placed anywhere, and moved around on, its page. At the bottom of the screen , process prompting is supplied in the form of 'visual storytelling prompts' which are modelled on a text-based writing program described by Holdich and Chung (2003); details of their motivation and design may be found in Madden (2007).

In order to better view and edit a shot, the user is required to 'jump into' it, whereupon the screen changes to the 'shot view' shown in Fig. 4. It is also possible to 'jump into' a shot in a second way, to write text for it. Here the picture is displayed in large view above a text entry box.

The pose and warp functions are located in this shot view, and the pre-supplied characters accessible from it. Characters were drawn in a deliberately simplified style, limiting the number of vector curves so as to make warping as straightforward as possible. The shot view also contains controls to scale artwork, change the order in which it is layered, set a background image, and change characters' colours. These artwork-related controls are presented in one tab; a separate tab gathers together the camera controls, namely zoom, translation and tilt.

The prototype exhibits a significant camera limitation which will be termed the 'constant background effect'. It consists of the fact that picture backgrounds are unaffected by zoom, translation or tilt, so that no matter how these camera parameters change, the background image resolutely retains a constant appearance. Characters and clipart, however, render correctly under camera changes.

\subsection{Process Design}

In the term in which the study took place, the class's literacy objectives included 'point-ofview story' writing, in which the objective is to tell or retell and incident from a particular character's viewpoint, focusing on reporting their thoughts, feelings, actions and reactions to events. One of the genres specified for study was myths, legends and fables; accordingly, Aesop's fable of the Fox and the Crow was chosen, and participants each asked to produce three short pieces of point-of-view writing for the story's beginning, middle and end in three consecutive weeks.

Participants were placed either in a control group, following a shared brain storming, individual writing approach, or an experimental software group, following an independent visualise-then-write approach. Both groups' sessions were led by a teacher-leader who has experience in teaching this age group at a different school. The investigator was present at all sessions to act as a facilitator.

The control process reflected the teacher-leader's preferred practice of first guiding a brainstorming period, to orient participants to the task and highlight useful words, and then initiating an independent work period in which participants wrote to the task identified in the 
brainstorm. It was intended that the control group be allowed to use the software after completing their three pieces of writing, so that they would not feel left out or marginalised.

The experimental process was chosen so that the final outcome would be a 'cartoon story' resembling an illustrated storybook, consisting of a series of pictures each with its own piece of text. It was intended that participants would first create their pictures and then 'jump into' each one in turn to enter the appropriate text, rather than, for example, create speech or thought bubbles on the pictures themselves. This choice was made so as to allow the text more scope to act as the kind of point of view writing identified above in which the character's narration can report on all aspects of an incident; speech or though bubbles were seen as constraining the role of the writing too much. In face, the majority of the captions did act exactly as speech bubbles, but some also served the former, more general, purpose.

Each group consisted of six participants from the school's only Year 5 class (ages 9-10 years); they were taken out of their normal class routine for the sessions. All participants used school laptops for their work; the pattern of use is summarised in Table 3 . So that experimental participants would not be starting from cold with totally unfamiliar software in their first writing week, they were given a half-hour software introduction, not related to the fable, in the week before the activity began.

The fable was split into three sections, and appropriate visual storytelling prompts created; these may be seen in Table 4. Each group followed their process for each story section in turn over three weeks, as shown in Weeks 1 to 3 in Table 3 . These weeks were planned to encapsulate fairly self-contained exercises; the intention was that in each one, the participants would write about a new stage in the story. This meant that the control group wrote the story in three separate chapters. The experimental group also had three separate prepare-then-write sessions, each focusing on a separate stage of the story, but in Week 3 the investigator was advised to collate their previous week's work so that participants could have a chance to finish text which they had begun entering for pictures they had made in Weeks 1 and 2.

The three-week approach of separating writing into discrete, short, sessions might seem to be placing overly tight strictures on students; however, it does reflect the kind of focused task which they were otherwise set. For example, a preparatory classroom observation session giving a sense of the tasks typically set for students showed that, given a simple theme, they were expected to be able to decide on appropriate content and transcribe it by hand in $15 \mathrm{~min}$. In this study, therefore, it was judged that a 15 min computer writing period, after content had been planned in an initial, focused, brainstorming or visualisation period, appeared reasonable and realistic.

\subsubsection{Initial Reactions to the Control Process}

It was found in Week 1 that the four participants able to be present in the control group did not use their time constructively, frequently moving off-task, suggesting inappropriate content and feeding off each other's disruptive behaviour. Despite the best attempts of the teacher-leader and investigator to engage them, several participants were observed to put little effort into their tasks. Two factors may have caused this response. First, the pilot study task was very obviously separate from all participants' normal school context: it was led by two visitors unconnected to the school, and the work produced did not form part of the whole class's portfolio. Secondly, some control participants may have viewed the process as too mundane to engage with, especially in such an out-of-context situation. 
As a stopgap attempt to better engage the control group, their arrangements were modified in Weeks 2 and 3, in two ways. First, it was the teacher-leader's and investigator's judgement that the control group's chance to use the software should be brought forward to Week 2, so that it could be used in that week as well as inWeek 3, as an incentive to stay on task. Although taking this time clearly reduced the time available for text generation, this reduction was judged acceptable given that the participants had used the extra time in Week 1 unconstructively. Secondly, one control group participant seemed especially disaffected at the prospect of typing at the laptop keyboard, so in Weeks 2 and 3 the teacher-leader acted as a scribe, typing the sentences which this participant dictated. It is also worth noting that several other participants in both groups, while not actually disaffected by the request to type, exhibited significant difficulty with the mechanics involved as though not at all used to entering non-trivial quantities of text.

\subsection{Character Manipulation}

Moving to consider the character pose and warp features, a sharp distinction emerges between participants who used the facility in mant of their pictures and those who did not. As shown in Table 5, half of the participants significantly posed or warped characters in $71 \%$ or more of their pictures, while the other half made changes $30 \%$ of the time or less, with one never deviating from the characters' default poses or expressions at all.

However, five of the participants produced one or two pictures making quite significant use of pose and warp. Fig. 5 highlights these. The other uses of pose and warp were not simply arbitrary or random; they too depicted the characters in ways which were relevant to the cheese, or the fox's head was tilted a little so as to be looking in the right direction.

It can therefore be seen that each participant made a significant number of pictures which used characters in or close to their default poses. In part, this may be due to the fact that these default poses were not all that neutral. The fox in particular was depicted as already wearing a reasonable interesting, that is non-neutral, expression, and was probably appropriate for use in a number of contexts 'straight off the shelf'. It must be noted that pictures using the default poses were not necessarily unimaginative; for example, one participant used the default front view fox but made it hide behind some grass in quite an imaginative way (see the top left picture in Fig. 6).

One interpretation of the high incidence of default, clipart-like, usage is to suggest that the pose and warp features were too advanced and/or difficult, and that the participants were disengaged with these features. If this were the case, however, one might expect to see many examples of random, seemingly pointless character manipulation, of characters turning multi-coloured or having their vector control points dragged at random. In fact, only one picture appears to show anything close to this, featuring a crow who has momentarily turned blue. The participant makes no reference to this change in their accompanying text.

A rival interpretation, therefore, lies in considering the importance of the notions of 'purpose' and 'utility' (Ainley, Pratt \& Hansen, 2006) when considering how particular software features may be relevant to a given activity. Loosely, this means that an activity is most likely to have learning value if pupils 'buy into' its outcome, perceiving it as purposeful and meaningful to them, and also see that the tasks within the activity have direct utility in achieving that outcome. It is very possible that here, the pose and warp features were seen as unnecessary, that is, lacking utility, in a significant number of situations, or that the default off-the-shelf representations were good enough. It would 
therefore be instructive to examine the impact of purpose and utility on the pose and warp features when designing future studies; Section 5 identifies some starting points.

\subsection{Camera Manipulation}

The camera translation and zoom features were reasonably well used; participants made use of a variety of shot distances, mainly in the long to mid shot range. Long shots were found to dominate, with five of the six participants making at least half of their pictures long shots. Close-ups are much rarer; three participants produced one each. This suggests that participants showed some ability to move beyond a single fixed perspective in order to better focus on salient story elements, but that this was not expressed as fully as it might have been, had, for example, more close-ups been deployed. Fig. 6 shows four examples of particularly effective choice of zoon; it can be seen from the accompanying text which the participants wrote that they were thinking about what to depict and how to depict it.

Camera tilt function was very rarely seen, although three experimental participants applied it in situations in which there was an obvious height element, for example looking down at the ground from a tree, or over the Fox's shoulder up at the Crow. This is suggestive that students grasped the idea of the tilt facility even if they did not apply it much.

Overall, the, it can be seen that the software's camera functionality was used, but perhaps not extensively. In interpreting the limited nature of its use, it is east to point to software limitations, particularly the constant background effect, which largely masked the effect of camera tilt and significantly affected zoom, particularly since no background images were supplied showing a close distance. However, depicting backgrounds in close-up is not impossible; greater flexibility can be achieved by assembling backgrounds from the bank of images supplied to the participants, and this is just what Fig.7 shows was done in some pictures, even though manually assembling a background by repeatedly choosing, inserting and scaling individual images is a more involved task than just choosing a single image.

As with pose and warp features, then, there may be more at work than just issues of functionality. Consistent with the preference for long shots noted above, Burn and Parker (2003b) too found a distinct tendancy for children to stick to fixed, long, camera perspectives when making visual stories. This motivates the questions of whether a different task might better highlight the utility of more varied camera perspectives, and if such a task would result in participants making fuller use of such features irrespective of details of functionality.

\subsection{Other software notes}

Considering editing and sequencing, the prototype software does not impose a strict notion of sequence; story stages are presented sequentially, but for each of these a user can make an arbitrary number of pictures and arrange them however they desire on the stage view screen. Indeed, one point of interest of the study was to see to what extent sequences arose out of the participants' work when they were not a prescribed feature.

The default behaviour of the software ${ }_{634}$ causes newly created pictures to appear in the stage view sequentially 'stacked up' on top of each other, each subsequent one slightly below and to the left of the last, until they are manually repositioned. Well-defined sequences can certainly be made by appropriate manual positioning, but this is by no 
means the only configuration of pictures which the stage view permits. Consequently, although all participants made use of the ability to move pictures around at the stage view, only one consistently arranged their pictures into a linear comic strip arrangement for all three story stages. Three other participants used the repositioning facility to generate clear left-to-right sequences for at least one of their stages, and the remaining two arranged each stage's pictures across the screen with no discernible sequence. In the majority of cases of well-defined left-to-right sequences, the order in which pictures were initially created is the same as the order in which they are finally presented at the stage view; the intended sequence thus seems to be inherent in the making of the pictures themselves, with participants having it in mind either openly or implicitly from the inception of each picture.

The stage view's explicit partitioning between story stages and screens was likely unhelpful; of the five experimental group participants who were present for all sessions, two chose to conclude their cartoon stories on the second stage screen, adding to the pictures already there and leaving the third stage screen blank. This is particularly notable in the case shown in Fig. 8, where the participant in question has very clearly chosen to show an unbroken sequence of pictures which spans the middle and end stages. The inference drawn here is that participants' desire to make a continuous sequence may conflict with the guiding prompt suggestion that each screen should contain only pictures for that stage, and that this prompt was ignored. Additionally, software logs show that participants very rarely requested the 'ideas', 'character' or 'camera' help prompts.

\subsection{Comparison of control and experimental stories}

Although the groups' products are dissimilar, it is meaningful compare them as stories and to ask if any differences arise in their narrative content. Both groups' stories contains elements not found in the original story; since each session involves writing from a character's point of view, new elements are virtually invited as writers consider a particular character's take on events. However, the evidence suggests that the content of the experimental group's stories is more on-topic than the control group's. Of the five experimental group participants present in the final week:

- three produced pictures and text showing and describing an end to the story which was largely in-line with the original;

- the remaining two produced pictures showing the main aspect of the story's end, to wit the crow dropping her cheese and the fox getting it, but did not get so far as to write any text for those pictures.

In contrast, three control group stories deviate from the original: two end differently, and one of these and another with the 'proper' ending introduce rather random events involving new characters. It is as though many of the participants generated ideas and text which serve as digressions or dilutions of the story, rather than as appropriate additions or developments. In the teacher-leader's opinion, the experimental group text contained more on-task descriptions appropriate to retelling the story. It seems as though these participants accepted and engaged with the story as it was told, rather than introducing other events in an attempting to change it. She also felt that these participants had immersed themselves in the story to a greater extent. In her words, "they were putting themselves in the picture".

Lastly, a marked difference also emerges when the groups' written text alone is compared; specifically, the control group text consistently adopts a past tense narrative whereas that 
of the experimental group oscillates between the present and the past tense, sometimes in the same piece of picture text. The past tense is entirely to be expected of the control group's writing, as it is the commonest way of writing a normal story and one which schools emphasise as part of the National Literacy Strategy. By comparison, experimental group participants seem to have had two conflicting narrative modes in mind; a substantial proportion of their picture text presents action as it happens, describing what the characters are thinking at the time of the picture, what they are doing, and what they can see. Other portions of text show one of the characters recounting events and actions in the past tense, much like a flashback and most unlike the usual content of speech and through bubbles; for example participant 4's "I looked into her eyes and thought that she would not give me the cheese so I thought of a plan to get it". It is almost as though the pictures are naturally prompting a present tense mentality which affects their text and sometimes overrides the tendency for prose to speak in the past.

Table 6 presents the figures; the Fisher-Freeman-Halton test returns a $98 \%$ probability that the difference seen is significant. Neither group was given explicit instruction as to which tense to adopt; although the visual storytelling prompts speak in the present tense, neither the guiding prompt nor the subsidiary help prompts are visible on the text entry screen. This suggests that the variation in tense results from the strong implicit ties between picture and text which the software process enforces. Supporting evidence for this comes from another notable feature of the experimental group's text: in contrast to a normal illustrated book, it is not independent of the visuals. Instead, many sentences implicitly rely on the pictures to show action, and to introduce objects and characters, and so written descriptions of action, and written introductions of things, are sparse. There are instead a great deal of references to "that fox", "this cheese", "I can see Nottingham from here", and so on, which rely on the appropriate picture to establish their context. This too suggests that the visual process is impacting upon the writing process, changing its output.

\section{Summary and Conclusions}

This paper has demonstrated that there is scope to consider new approaches to designing story visualisation tools for children. Given continued policy-maker and practitioner interest in utilising moving image concepts for English teaching, finding opportunities to extend and improve ICT tools for such purposes has direct educational relevance.

One approach for a new ICT tool has been proposed and prototyped. Despite some problematic usability issues, the whole software concept has been validated; it allows learners to make visual stories by posing and warping characters, placing them in scenes, choosing a camera angle, and sequencing pictures. All participants who used the software proved able to use its features to make several pictures which incorporated characters and images placed on a background image. As noted, all adopted a simple clipart-like approach, by not posing or warping characters, in a significant number of their pictures. However, there are examples which show participants using the pose and warp features to go beyond the capabilities afforded by a clipart-based approach at least some of the time; all but one participant seemed to use these functions to achieve some deliberate effect in some of their pictures. There is also evidence that participants had at least some understanding of constructing camera shots for deliberate effect, most especially using zoom and to a small extent camera tilt. However, they more often stayed at a default long shot distance. This high incidence of default characters and camera shots may be interpreted in terms of notions of purpose and utility (Ainley et al., 2006) rather than, for 
example their tendency to direct their effort into producing 'on-topic' interpretations and retellings of the story.

Concerning the prototype's effect on writing, it can be seen that experimental group's picture-making process resulted in quite different writing to the control's. Their pictures and text were judged by the teacher-leader to be more on-topic, as compared to the control group's brainstorm suggestions and text. However, the experimental group displayed uncertainty as to which tense to use, produced less text, and made frequent implicit textual references to their pictures. Further, no significant difference in use of visual language was found between the groups. Currently, it is not possible to tell the extent to which these differences 774 arose from the visual facilities, and how much they were caused by the process support offered, although it is suggestive that the former were used purposefully by participants and the latter was apparently not.

With an eye to the future, the ideas of purpose and utility noted above may give a rationale for the desire to extend and 'strengthen' the software concept by allowing learners to place their own characters into the tool. Arguably, being able to pose and warp one's own creation would increase the meaning which one attatches to the activity. If this is combined with a stronger sense of producing a product for a meaningful audience such as younger pupils, as Ainley et al. (2006) describe in relation to geometry software and Parker (1999) relates in the context of telling a visual story, then it may be that posing and warping of characters naturally increases. Certainly it would be interesting to see if this kind of activity led to a greater take-up of these features, of learners 'constructing a utility' (Ainley et al., 2006) of pose and warp and from that perhaps a more general 'utility of depiction' for visual storytelling. Such an understanding would also ideally include an appreciation of the utilities of different kinds of camera shot, for example the levels of zoom, and also of the different narrative effects which can be achieved by varying the way in which shots are edited together (May, Dean, \& Barnard, 2003, provide a useful condensed review of some of the 'craft knowledge' and theory relating to sequencing and editing). Different or additional software camera features may assist in this; one might envisage a more truly 3D scene which one could fly a camera around, or of changing the 'infinite page' metaphor into something more like a paper cutout theatre stage which could provide a schematic scene layout allowing one to choose from a specific set of camera angles. Here too it would be useful to see if other task designs, again perhaps using some notion of a genuine audience, led to an increased variety of camera shots and an increased focus on sequencing and editing. Of course, all such speculation needs to be tested, and the authors look forward to the opportunity of arranging further studies and building more polished software which is afforded. 


\section{References}

Ainley, J., Pratt, D., \& Hansen, A. (2006). Connectigng engagement and focus in pedagogic task design. British Educational Research Journal, 32(1).

Bailey, B. P., Tettegah, S. Y. and Bradley, T. J. (2006), Clover: Connecting Technology and Character Education Using Personally-Constructed Animated Vignettes. Interacting with Computers, 18 (4).

Barrance, T. (2004), Making Movies Make Sense. Media Education Wales. British Educational Communications and Technology Agency (Becta) (2002), Computer Games in Education project: Report. Accessed from 'all publications' section of http://partners.becta.org.uk, April 2007.

Bennett, D., Brunner, C., Hupert, N. and Meade, T. (2000). Children's Use of the Internet for Design and Invention. Paper presented at the International Forum of Researchers on Young People and the Media, Sydney. bfi Primary Education Working Group (2003), Look Again! A Teaching Guide to Using Film and Television with Three- to Eleven-year-olds. British Film Institute.

Biever, C. (2003). The animation game. New Scientist Magazine, October 2003. Birmingham, P. and Davies, C. (2001), Storyboarding Shakespeare: Learners' Interactions with Storyboard Software in the Process of Understanding Difficult Literary Texts. Journal of Information Technology for Teacher Education, 10(3).

Burn, A. and Leach, J. (2004), ICT and Moving Image Literacy in English. In Andrews, R. (Ed.) The Impact of ICT on Literacy Education, Routledge- Falmer, London.

Burn, A. and Parker, D. (2001), Making Your Mark: Digital Inscription, Animation and a New Visual Semiotic. Education, Communication and Information (ECi), 1 (2).

Burn, A. and Parker, D. (2003a), Analysing Media Texts. Continuum, London and New York.

Burn, A. and Parker, D. (2003b), Tiger's Big Plan: Multimodality and the Moving Image. In Jewitt, C. and Kress, G. (Eds.) Multimodal Literacy, Peter Lang, New York.

Davis, A. M. (1985), The Canonical Bias: Young Children's Drawings of Familiar Objects. In Freeman, N. H. and Cox, M. V. (Eds.) Visual Order: The Nature and Development of Pictorial Representation, Cambridge University Press.

Donovan, P. (2003), Digital Video Proves "Super Tool" for Disaffected Stus22 dents. The University at Buffalo Reporter, 34 (30).

Erstad, O. (2002), Norwegian Students Using Digital Artifacts in Project- Based Learning. Journal of Computer Assisted Learning, 18 (4).

Fee, S. and Fee, L. (2003), Pedagogical Approaches for the Use of Digital Video. In Proceedings of the Society for Information Technology and Teacher Education (SITE) Conference 2003.

Golomb, C. (1999), Art and the Young: The Many Faces of Representation. Visual Arts Research, 25 (1). 
Holdich, C. E. and Chung, P. W. H. (2003), A 'Computer Tutor' to Assist Children Develop Their Narrative Writing Skills: Conferencing with HARRY. International Journal of Human Computer Studies, 59 (5).

MacGregor, S. K., (2003), The Computer Paint Program: A Palette for Facilitating Visual and Verbal Literacy. Computers in the Schools, 19 (1).

Madden, M., Chung, P. W. H. and Dawson, C. (2004), Storytelling, Storyboarding, Storywriting: Proposing a New Computer Tool for Narrative. In Proceedings of the 7th IASTED International Conference on Computers and Advanced Technology in Education, International Association of Science and Technology for Development (IASTED).

Marsh, J. and Thompson, P. (2001), Parental Involvement in Literacy Development: Using Media Texts. Journal of Research in Reading, 24(3).

Matthews, J. and Jessel, J. (1993), Very Young Children Use Electronic Paint: A Study of the Beginning of Drawing with Traditional Media and Computer Paintbox. Visual Arts Research, 19 (1).

McCloud, S. (1993), Understanding Comics: The Invisible Art. HarperPerennial, New York.

Office for Standards in Education (Ofsted) (2005), Annual Report of Her Majesty's Chief Inspector of Schools 2004/05. The Stationary Office (TSO).

Oldham, J. (1999), The Book of the Film: Enhancing Print Literacy at KS3. English in Education, 33 (1).

Parker, D. (1999), You've Read the Book, Now Make the Film: Moving Image, Media, Print Literacy and Narrative. English in Education, 33 (1).

Parker, D. (2002), Show Us a Story: An Overview of Recent Research and Resource Development Work at the British Film Institute. English in Education 36 (1).

Reid, M., Burn, A. and Parker, D. (2002), Evaluation Report of the Becta Digital Video Pilot Project. British Film Institute.

Sefton-Green, J. and Parker, D. (2000), Edit-Play: How Children use Edu- tainment Software to Tell Stories. British Film Institute.

Sefton-Green, J. (1999), From Hardware to Software: The Resource Problem? In SeftonGreen, J. (Ed.) Young People, Creativity and New Technologies: The Challenge of Digital Arts, Routledge, London and New York. 


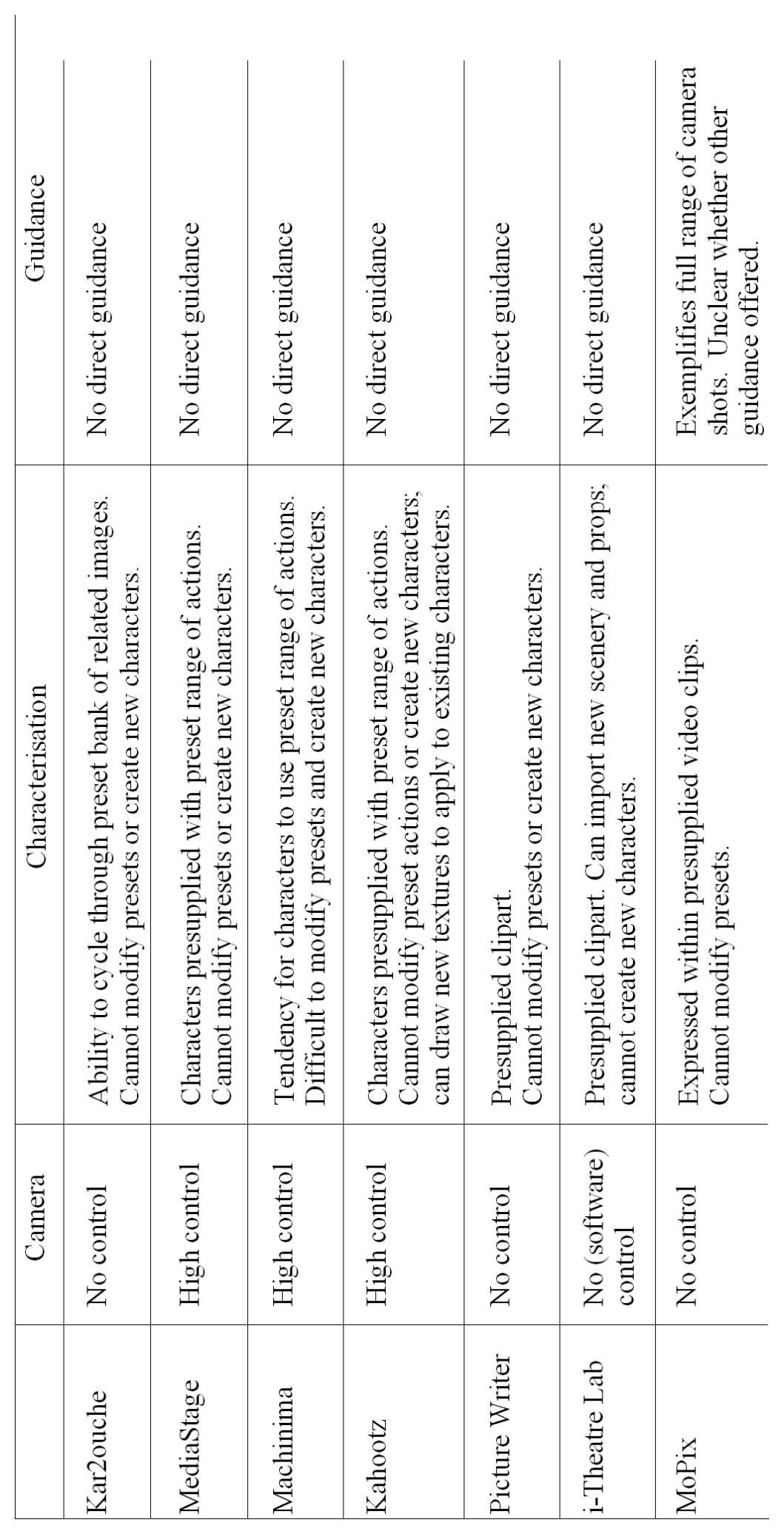

Table 1 Summary of content-centred software tendencies 


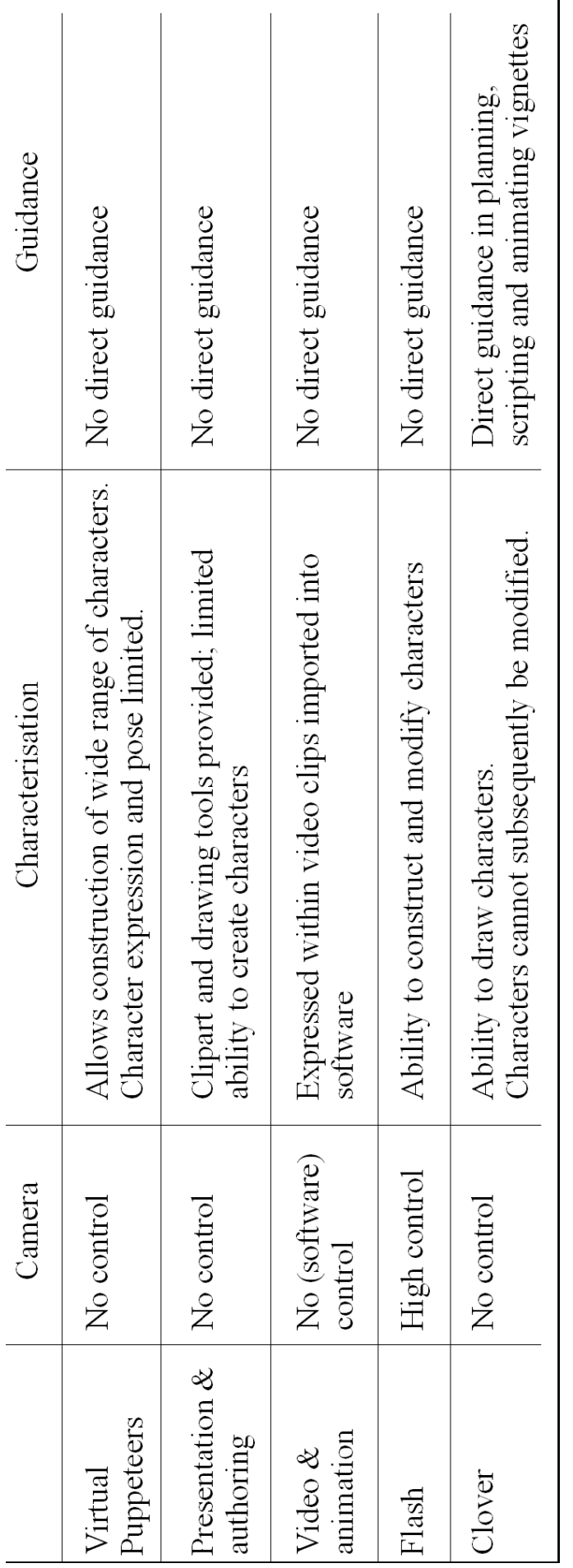

Table 2 Summary of build-centred software tendencies 


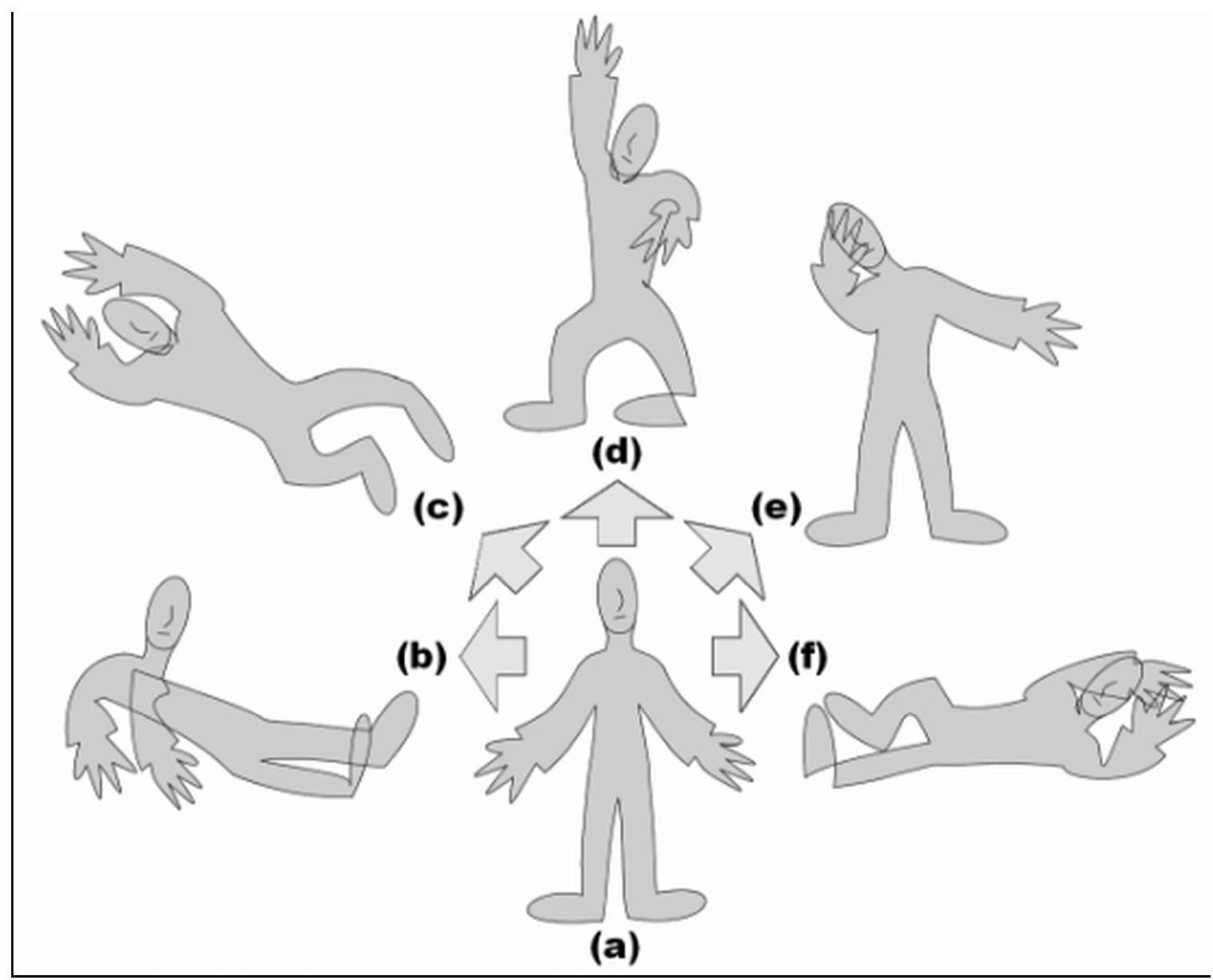

Fig. 1. When a single initial drawing (a) is mapped to a skeleton under the enhancedfrontal-orientation approach, many different images can easily be produced ((b) to $(f))$. 


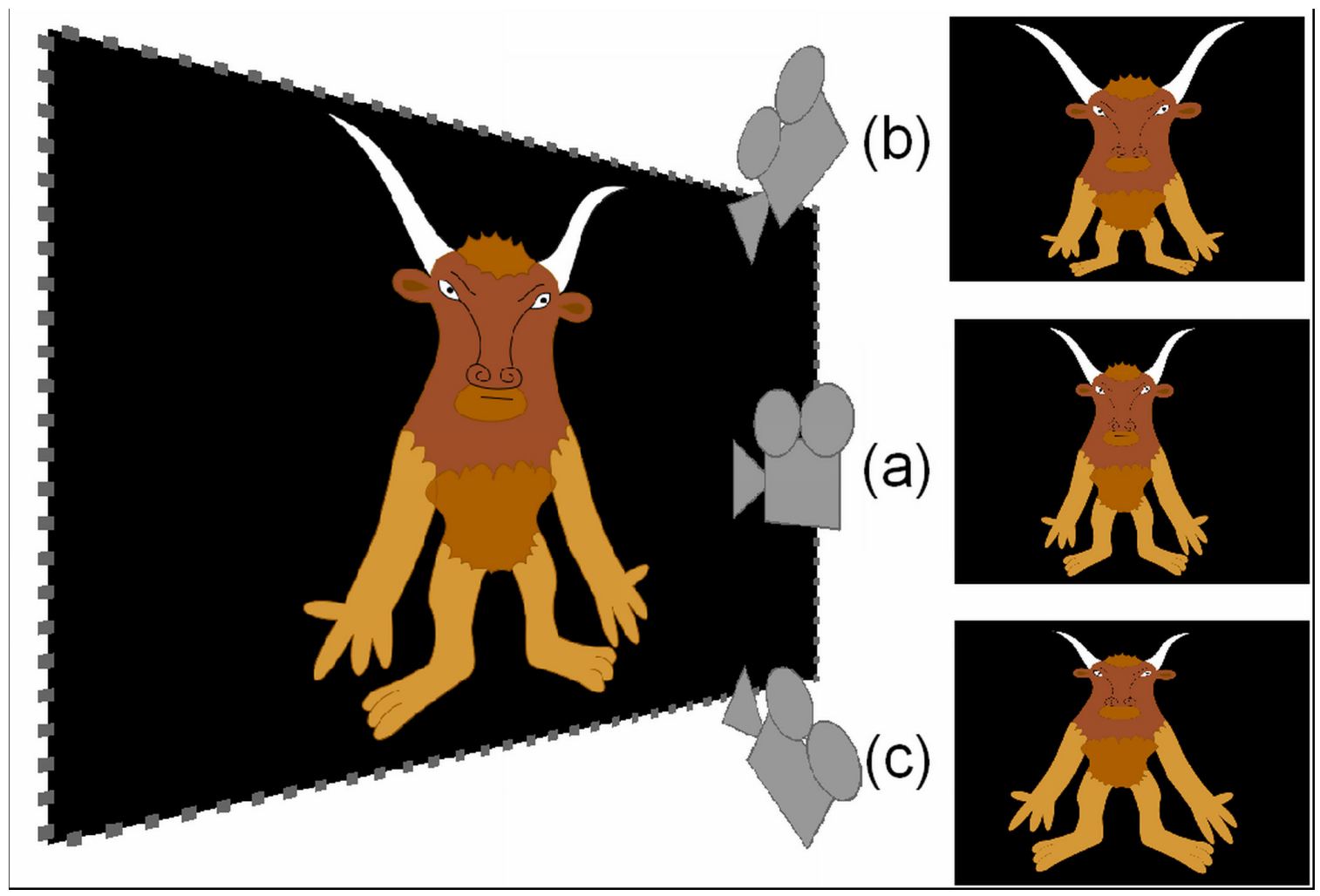

Fig. 2 Indication of the conceptual model used for limited camera functionality. The camera can translate parallel to the plane of an infinite page which can hold characters, clipart and a background; characters and clipart can bend and rotate out of the plane of the page but remain anchored at a constant depth. The default straight-on camera configuration is shown in (a); (b) and (c) show the combinations of tilt and translation necessary for high and low angle shots, respectively. 


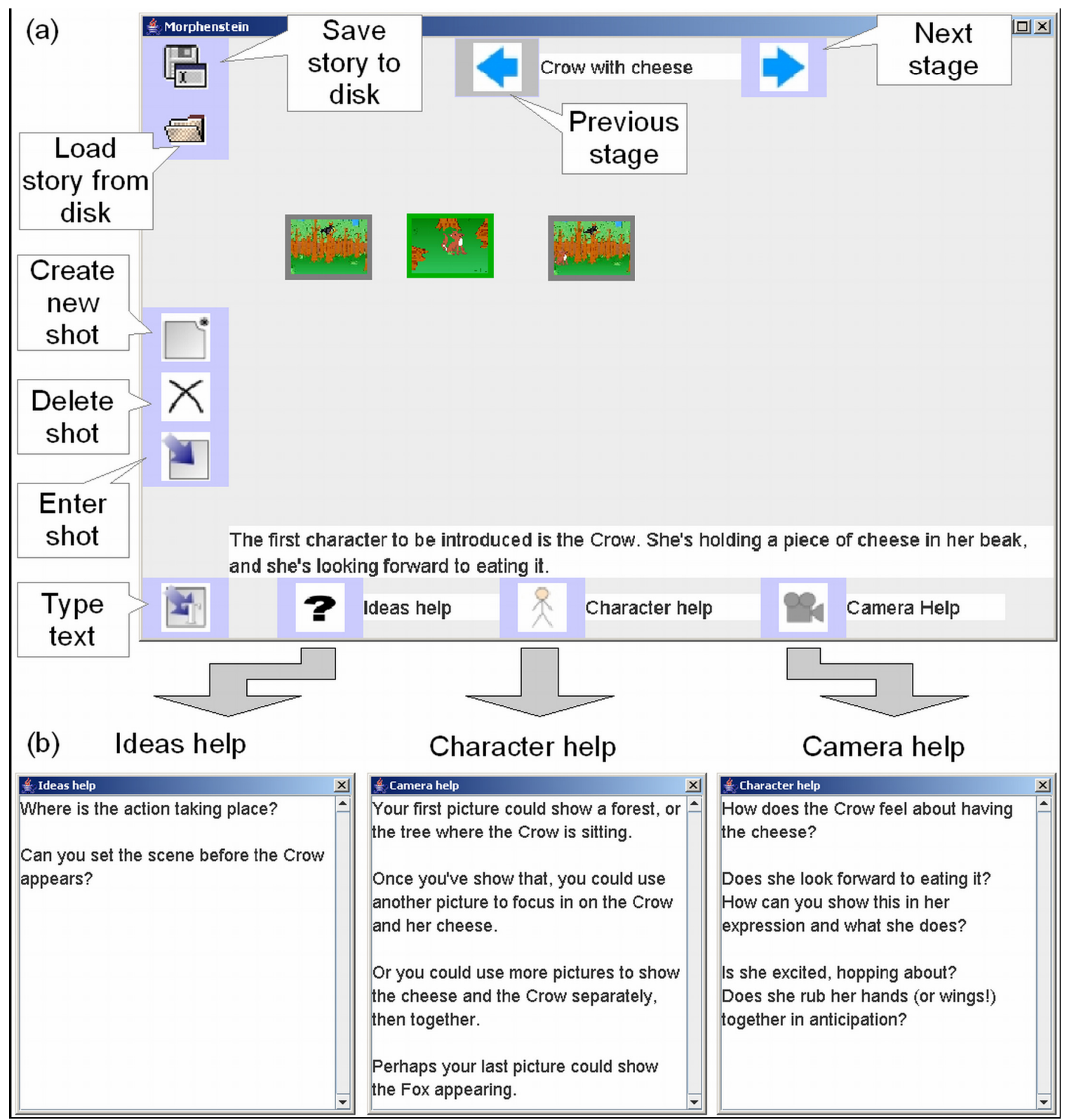

Fig. 3. (a) A typical 'stage view' screen, with the main visual storytelling prompt to be seen to the bottom. The three subsidiary help prompts are shown in a smaller window when the user clicks on the relevant button. As with HARRY, at most one of these extra help windows is shown at any one time; for convenience all three are collected together in (b). 


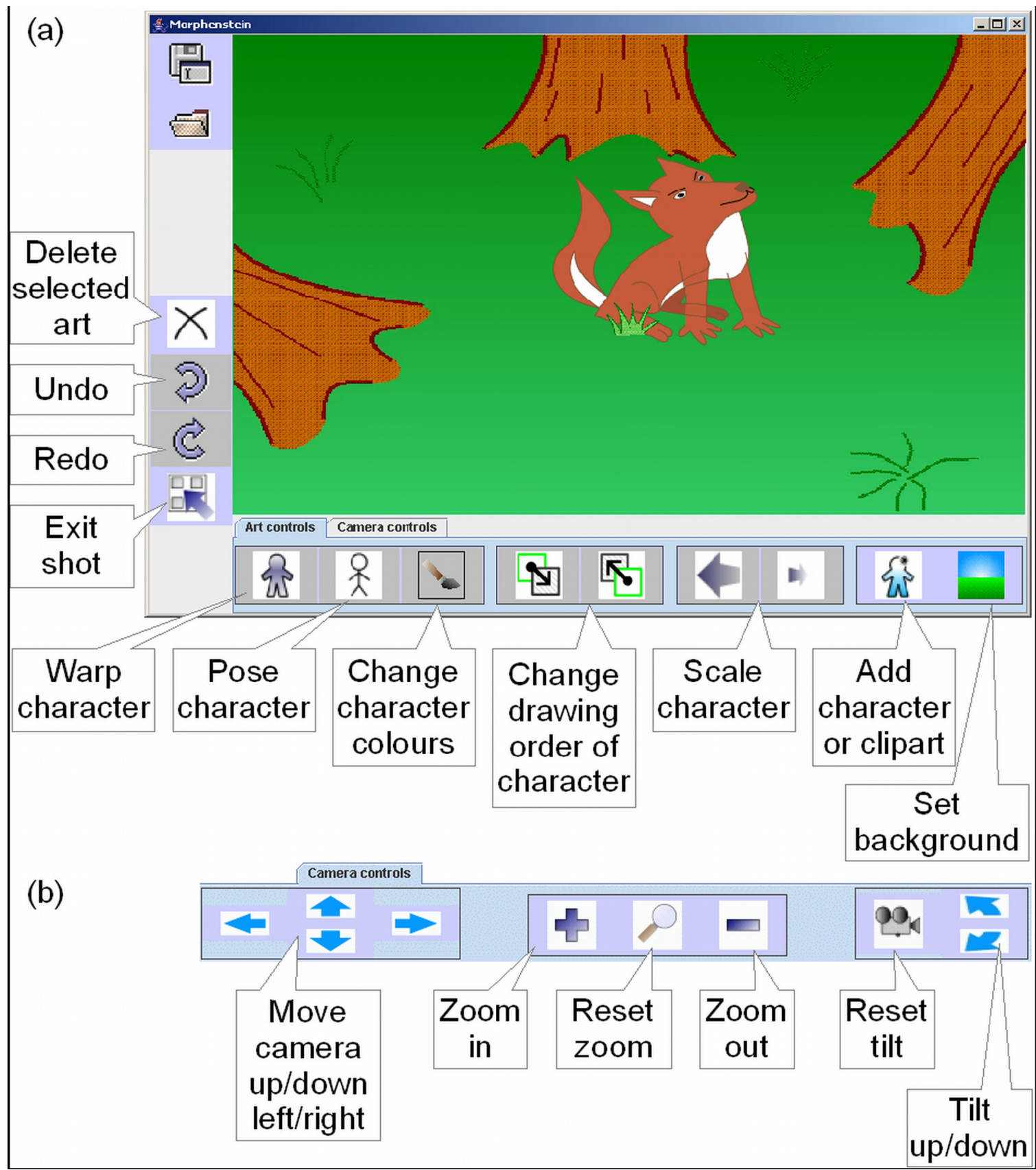

Fig. 4. (a) A typical 'shot view' screen, where the user can manipulate artwork and backgrounds, and change the camera view. These functions of artwork manipulation and camera control are mediated by tabs at the bottom of the screen; (a) includes the former tab, and the latter is shown in (b). 


\begin{tabular}{|c|c|c|c|c|}
\hline \multirow[b]{2}{*}{ Preparation week } & \multicolumn{2}{|c|}{ CONTROL GROUP } & \multicolumn{2}{|c|}{ EXPERIMENTAL GROUP } \\
\hline & & & 30 minutes & $\begin{array}{l}\text { software } \\
\text { introduction }\end{array}$ \\
\hline $\begin{array}{c}\text { Week } 1 \\
\text { Crow with cheese } \\
45 \text { minutes }\end{array}$ & $\begin{array}{l}30 \text { minutes } \\
15 \text { minutes }\end{array}$ & $\begin{array}{l}\text { brainstorm/plan } \\
\text { write story }\end{array}$ & $\begin{array}{l}30 \text { minutes } \\
15 \text { minutes }\end{array}$ & $\begin{array}{l}\text { make cartoons } \\
\text { write captions }\end{array}$ \\
\hline $\begin{array}{l}\text { Week } 2 \\
\text { Crow is conned } \\
45 \text { minutes }\end{array}$ & $\begin{array}{l}20 \text { minutes } \\
15 \text { minutes } \\
10 \text { minutes }\end{array}$ & $\begin{array}{l}\text { brainstorm/plan } \\
\text { write story } \\
\text { software play }\end{array}$ & $\begin{array}{l}30 \text { minutes } \\
15 \text { minutes }\end{array}$ & $\begin{array}{l}\text { make cartoons } \\
\text { write captions }\end{array}$ \\
\hline $\begin{array}{c}\text { Week } 3 \\
\text { The Fox gets the cheese } \\
45 \text { minutes }\end{array}$ & $\begin{array}{l}20 \text { minutes } \\
15 \text { minutes } \\
10 \text { minutes }\end{array}$ & $\begin{array}{l}\text { brainstorm/plan } \\
\text { write story } \\
\text { software play }\end{array}$ & $\begin{array}{l}30 \text { minutes } \\
15 \text { minutes }\end{array}$ & $\begin{array}{l}\text { make cartoons } \\
\text { write captions }\end{array}$ \\
\hline
\end{tabular}

Table 3 Process design for the prototype study. 


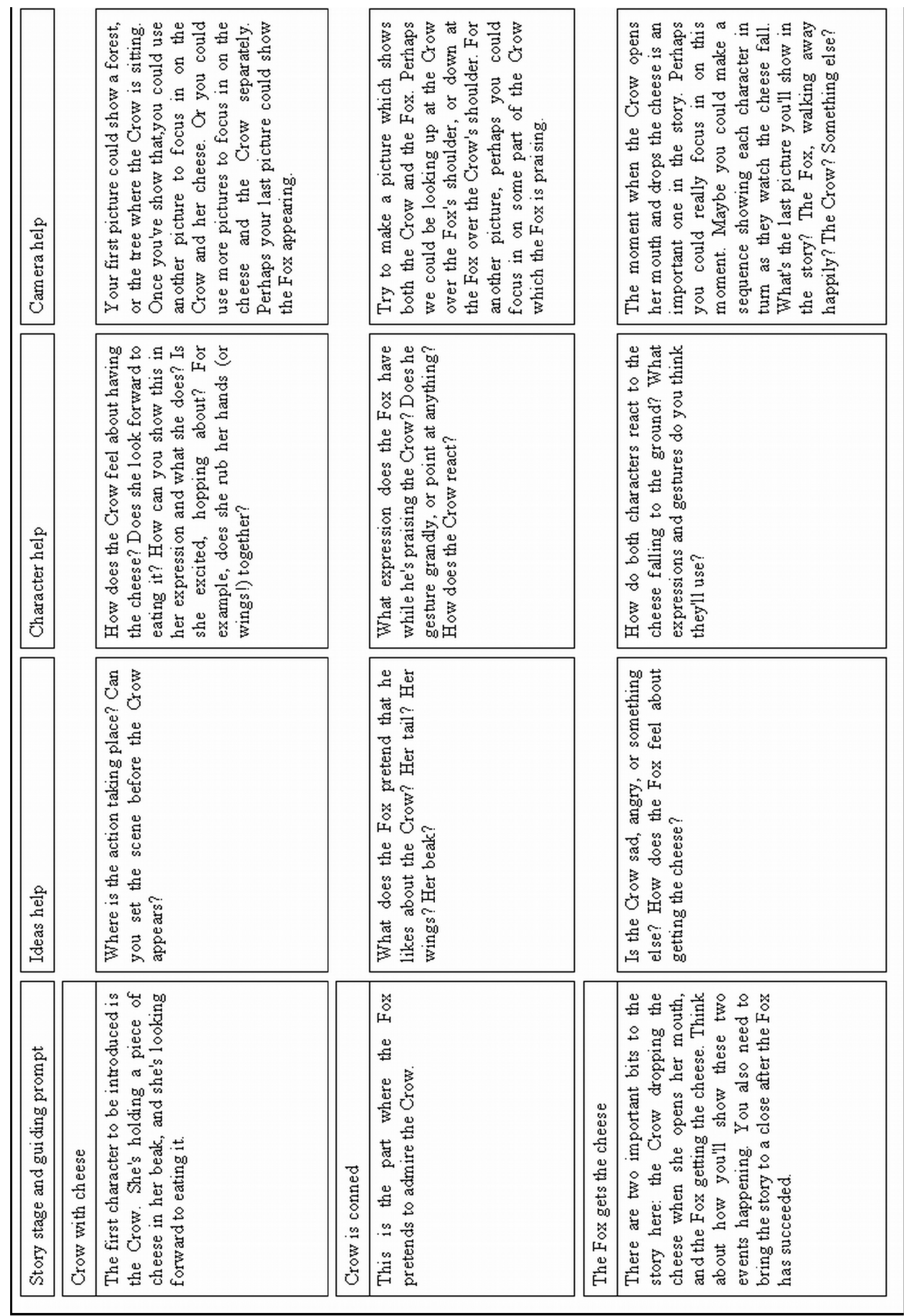

Table 4 Visual storytelling prompts designed for the fable of the Fox and the Crow 


\begin{tabular}{|cccc} 
Participant & $\begin{array}{c}\text { Number of pictures } \\
\text { with significant } \\
\text { pose or warp }\end{array}$ & $\begin{array}{c}\text { Total number of } \\
\text { pictures made }\end{array}$ & Percentage \\
\hline 4 & 7 & 9 & $78 \%$ \\
1 & 3 & 4 & $75 \%$ \\
5 & 5 & 7 & $71 \%$ \\
3 & 3 & 10 & $33 \%$ \\
2 & 1 & 6 & $17 \%$ \\
6 & 0 & 6 & $0 \%$ \\
\hline
\end{tabular}

Table 5 Experimental group use of pose and warp 

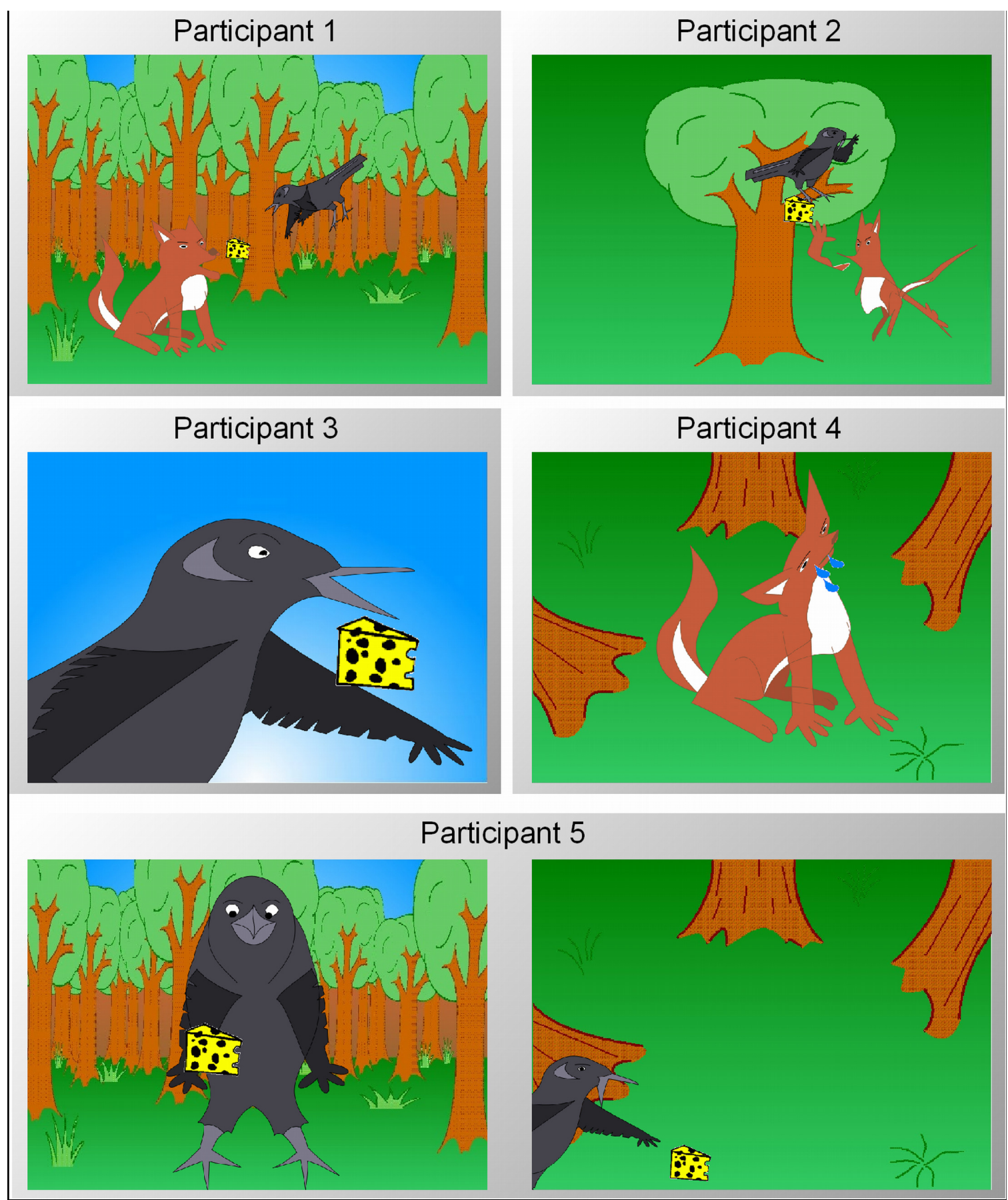

Fig. 5. Six notable examples making use of non-default poses and warps. 


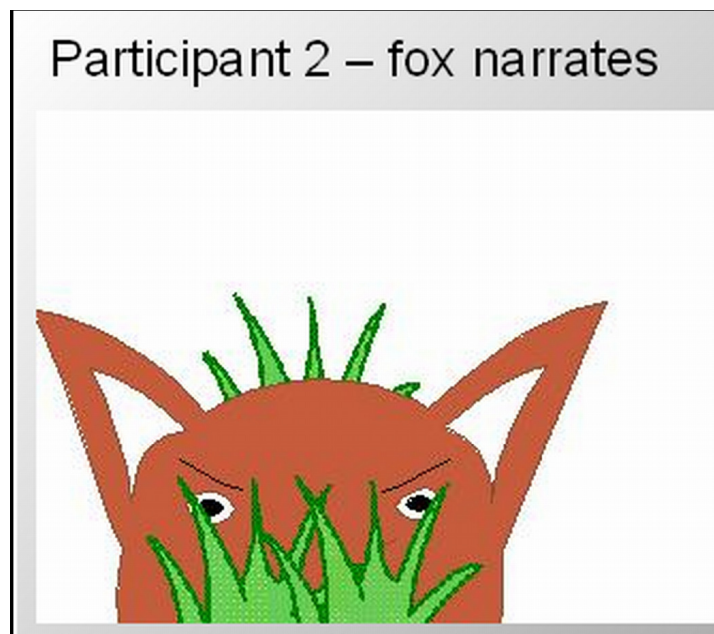

I am spying on the crow because she has got cheese that I want.

\section{Participant $4-$ fox narrates}

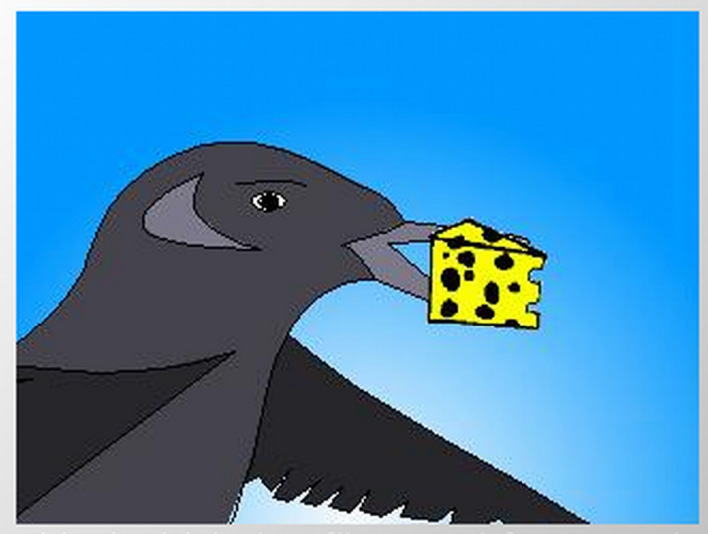

I looked into her [the crow's] eyes and thought that she would not give me the cheese so I thought of a plan to get it

\section{Participant 3 - crow narrates}

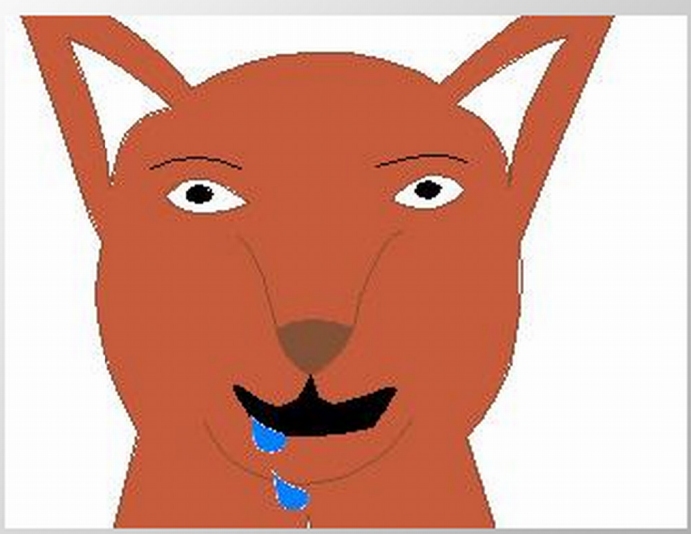

Look at that fat stupid ugly fox dribbling with his mouth open he's such a pig. How dare he think he can have my nice chunk of cheese. He looks so ugly I don't even feel sorry for him. It's his fault he hasn't got any nice lovely cheese he should look harder next time.

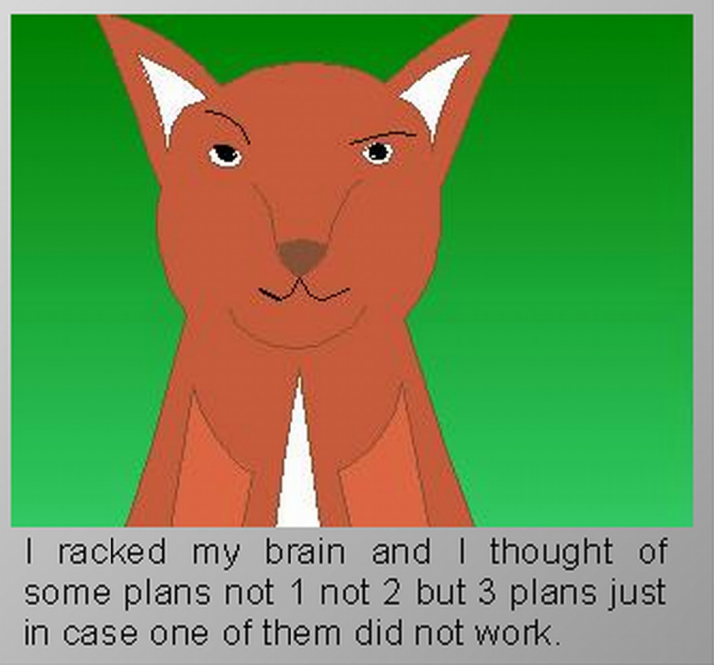

Fig. 6. Four pictures, together with captions, which when taken together demonstrate that participants have used zoom to focus in on a specific element of the story, and to direct viewers' attention to it. 


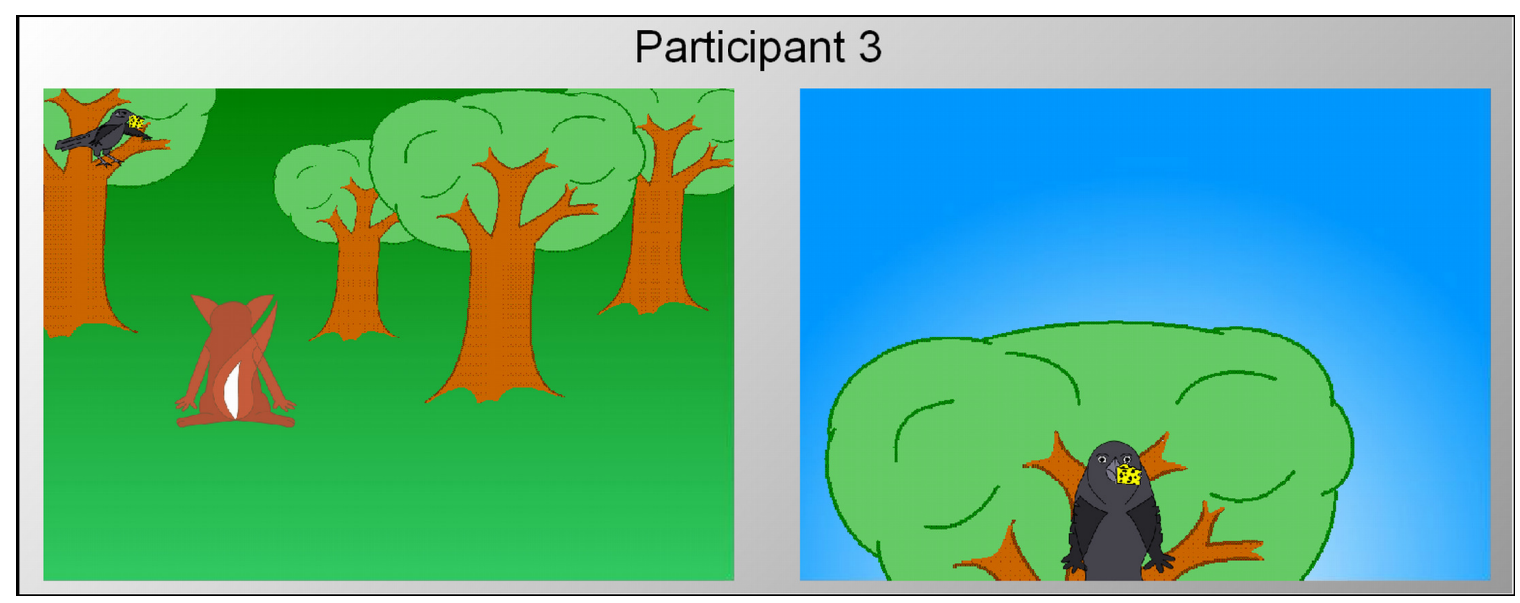

Fig. 7. Two examples in which a participant has assembled a background to their scene by combining simple elements.

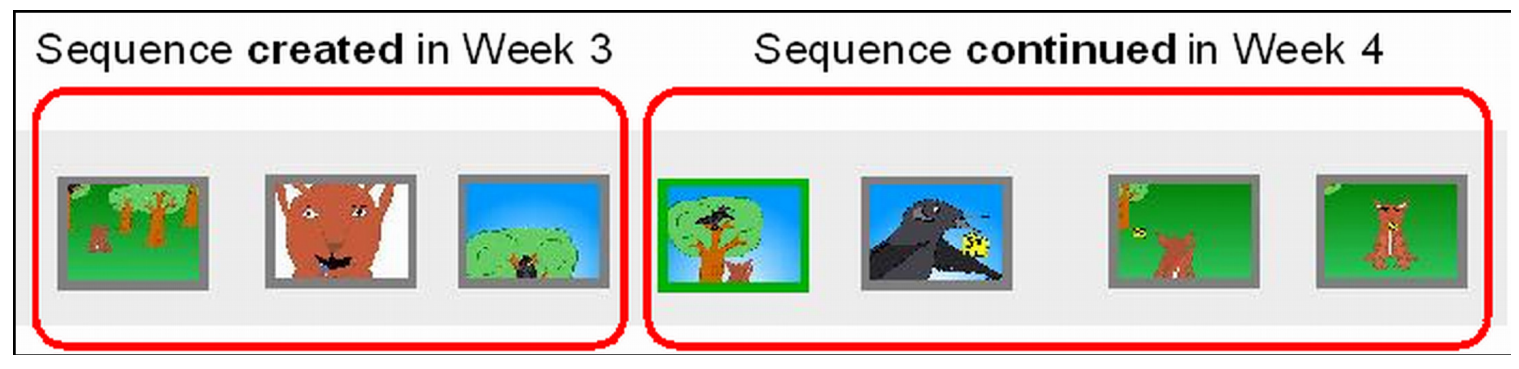

Fig. 8. An example of a participant ignoring the partitioning of story stages between different screens in favour making an unbroken sequence. The leftmost three pictures were created in Week 2 , and the rightmost four, which complete the story, in Week 3. However, all pictures were placed in the middle stage, leaving the final stage view screen blank.

\begin{tabular}{|l|c|c|c|} 
& Consistent past & Consistent present & Mixed \\
\hline Control & 6 & 0 & 0 \\
\hline Experimental & 1 & 2 & 3 \\
\hline
\end{tabular}

Table 6 Groups' use offense 